\title{
Effectiveness of Hybrid Dynamic Assessment in L2 learners' descriptive writing development
}

\author{
Roohani, Ali $\bowtie$ \\ Shahrekord University, Iran (roohani.ali@gmail.com) \\ Shafiee Rad, Hanieh \\ Shahrekord University, Iran (Haniyeshafieerad@gmail.com)
}

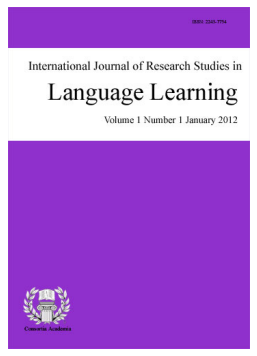

ISSN: 2243-7754 Online ISSN: 2243-7762

OPEN ACCESS

\section{Abstract}

It is required that second/foreign (L2) language learners learn how to write effectively in L2 through effective instruction. Also, it is crucial for them to learn how to assess their writing skill as a medium of human communication. Dynamic Assessment (DA) is a relatively new way of assessing language, offering potentials for L2 learners. This study was intended to examine the effectiveness of Hybrid Dynamic Assessment (HDA), in comparison with a non-HAD, on the L2 learners' descriptive writing, which is so important for intermediate-level L2 learners. To this end, 40 Iranian intermediate EFL learners were selected through a placement test to go through HAD and non-HDA instructions in two groups (experimental and control groups respectively). To collect data, two descriptive essays and a researcher-made questionnaire were used. The analysis of covariance on the descriptive essay scores in the pretest and posttest phases showed that the use of HAD instruction had a significant impact on the EFL learners' performance in the descriptive writing. Similarly, $t$-test results showed that such subcomponents of writing as function and content, organization, coherence, sentence construction and vocabulary improved more through such an instruction. Moreover, the analysis of data from the questionnaire demonstrated that the EFL learners in the HAD group evaluated the proposed HDA model as a means of assessing their writing positively. Findings suggest the use of HDA as an alternative assessment to move away from the traditional way of assessment to develop different types of L2 writing.

Keywords: descriptive writing; L2 learners; Hybrid Dynamic Assessment 


\section{Effectiveness of Hybrid Dynamic Assessment in L2 learners' descriptive writing development}

\section{Introduction}

Writing is a skill that is grounded in the cognitive domain. It involves learning, comprehension, application, and synthesis of new knowledge. According to Suleiman (2000), writing is a central element of language learning in English as a foreign language (EFL) contexts. It facilitates language learning (Deshler, Palincsar, Biancarosa, \& Nair, 2007). Also, language learners' pedagogical achievement across content areas sometimes depends on their ability to express knowledge through writing (Mason, Benedek-Wood, \& Valasa, 2009). But many EFL students and even teachers have difficulty in effective planning, composing, and evaluating their writings. As Suleiman (2000) points out, EFL teachers and students pay scant attention to the multidimensional nature of writing in instructional methods, evaluation procedures, and language development. One type of evaluation is through testing. Testing in language learning, mainly writing skills; is an inseparable part of the learning/teaching process; it can help in evaluating the gained knowledge and in promoting the quality of teaching and learning (Pilipović, 2017). Moreover, one form of testing currently used in many educational contexts to make decisions regarding learners' writing success is standardized or static testing, but there has been a move from static testing, where the examiner presents items to the learner and records his or her response without any attempt intervene to change guide or improve the learner's performance (Tzuriel, 2000), to new forms of assessment in recent years.

Assessment has been defined as a process of gathering information from multiple sources for the purpose of making decisions regarding student performance and/or instruction (Brown, 2003). Testing, on the other hand, is "a special form of the assessment administered under contrived circumstances" (Kizlik, 2009, p. 1). Consequently, tests can be regarded as non-natural methods of gathering information on learners' performance, and should, therefore, be employed in conjunction with other assessment methods. A newly developed way of assessing language is DA. DA is defined as an interaction between an examiner-as-intervener and a learner-as-active participant, which seeks to estimate the degree of modifiability of the learner and the means by which positive changes in cognitive functioning can be induced and maintained (Lidz, 1987). It offers the unification of assessment and instruction. "This integration occurs as intervention embedded within the assessment procedure in order to interpret an individual's abilities and lead them to higher levels of functioning" (Poehner, 2008, p. 5).

As Ableeva (2009) states, the development of DA rests on the prior and successive appearance of a few fundamental ideas that are seen as essential and compelling. They include the concepts of learning potential, educability, the Zone of Proximal Development (ZPD), and mediation (CarlHaywood, 2012). DA can take place through ZPD. In fact, within the learners' ZPD, learners use their existing knowledge to develop what they have not yet mastered independently (Nassaji \& Tian, 2010). In light of the above issue, there are two main models of DA: interventionist and interactionist. The interventionist model of DA is similar to the standard testing but it focused more on the measurement. The interactionist model of DA focus is more on the social interaction of the students and the mediator (Lantolf \& Thorne, 2004). Nonetheless, a new model of DA, HAD, has recently been proposed to integrate aspects of both interactionist and interventionist models of DA. HDA includes the characteristic of the interventionist DA model as well as an interactionist DA component manifested in the spontaneous interaction between the mediator and the student socio-cultural interaction.

Unfortunately, the proliferation of research addressing second/foreign (L2) writing has not yet been paralleled with the same enthusiasm to find writing assessment methods reflecting the socio-cultural nature of learning, which can be used as an alternative to standardized testing. Perhaps, the proposed HDA assessment method can be put into effect to assess EFL writing and overcome some of the problems associated with the 
currently used standardized testing of writing, which mainly ignores promoting language learners' writing development. However, little research has probed the effectiveness of HDA with respect to L2 descriptive writing skill. Like expository and argumentative writings, descriptive writing is a fundamental form of writing and it is very important for intermediate-level L2 learners since all types of writing include some elements of descriptive writing that cause a reader to see, think, feel, and react (Meyers, 2009). At first glance, it seems simplistic for academic discourse, yet it is "fundamental and the best way to lay the foundation of the writer's craft" (Meyers, 2009, p. 245). Thus, the current study aimed to investigate the effect of using HDA assessment on Iranian EFL learners' descriptive writing and evaluate the proposed HDA model as a means of assessing their writing

\section{Literature review}

There are three waves in the history of writing assessment (Yancey, 1999). The first wave, which started in 1950 and lasted until 1970, was the form of the objective test in assessing writing. The second wave, which started in 1970 and lasted until 1986, holistically scored essay. The third wave, which started from 1986 until the present time, was the portfolio and pragmatic assessment. However, Yancey's (1999) third wave could actually generate a fourth wave starting from 2000 to the present time. During this wave, writing assessment, research appeared to be concentrating on finding alternative methods that focused on the social aspects of writing assessment including the interactive relationship between the examiner and the examinee. Historically, that is why the concept of DA has become popular in recent years.

DA is basically rooted in a theory of the famous Russian psychologist Vygotsky and Sociocultural Theory of Mind (SCT) and ZPD (Vygotsky, 1978). DA is a form of assessment in which the weak features of the language ability, including writing ability of students, are recognized and more attention is paid to those parts. In this way, the students are assisted in case of their obstacles. The assessment in DA is not separate from instruction, but they come together and a mixture of these two results in a better outcome. In other words, as Haywood, Brown, and Wingenfeld (1990) put it, DA emphasizes the optimal performance under some specified conditions, rather than simply identifying the current level of performance.

Regarding DA as a new wave in assessing, research on it can be categorized into two main areas: initial work on DA through the decades of the 70s and 80s and more current research that appeared in the past two decades. Earlier works on DA in the 70s (e.g., Feuerstein, Rand, \& Hoffman, 1979; Cormen \& Budoff, 1973) and 80s (e.g., Joseph, Campione, \& Brown, 1987; Lidz, 1987) was more engaged in examining DA as a means to diagnose cognitive and intelligence strengths of children with mental deficiencies. They seemed to target more or less a similar population; namely, children with learning problems and low achievements at schools. However, more recent studies on DA mainly focus on the implementation of DA in different L2 learning contexts.

Regarding the recent research, there are two main models of DA: the interventionist and interactionist models (Lantolf \& Thorne, 2004). The interventionist approach applies the mediation method by using standardized administration procedures and creates a form of guidance to generate results that can be used to assess or measure the students' performance for a future test. In other words, interventionist DA emphasizes quantifying or speed learning. This approach focuses on the amount of guidance needed by the students to achieve the goal quickly and efficiently. On a different note, interventionist attempts to provide valid and reliable evidence of students' development by quantifying their performance (Sadek, 2015). On the other hand, Interactionist DA focuses on a qualitative analysis of the ZPD (Pohner \& Lantolf, 2005, p. 239), which Vygotsky (1978) defined as "the distance between the actual developmental level as determined by independent problem solving and the level of potential development as determined through problem-solving under adult guidance or in collaboration with more capable peers" (p. 86). Because of the weakness of the interactionist and interventionist, HDA was introduced and advocated by researchers and scholars such as Nehal S. Sadek in 2011. The suggested model is rooted in Vygotsky's SCT and ZPD (Sadek, 2011). 
In the L2 context, several studies have been conducted using DA. Xiaoxiao and Yan (2010) used DA to find out the relationship between methodology and epistemology. The study focused on the framework or process of writing instruction of English that adopted the principles of DA. The study showed that the dialogic way of teaching in DA had a significant role in improving the Chinese English major students' writing interest as well as their competence. Also, Sadek (2015) had a qualitative study on the impact of DA on the writing of L2 learners. The participants included six Egyptian citizens enrolled in the English Language Institute at The American University in Cairo. The result showed that DA had a positive impact on the content, language, and the organization of the ESL learners' writing. It had also reported that the students and teachers have positive evaluation since it allowed the students to focus on their individual weakness. Finally, Miao \& Lv (2013) performed a study of DA in constructing writing frameworks. By integrating the sandwich cake stages (pre-writing-mediation-post-writing), the study investigated the implementation of writing process framework into the dialogue centered ESL writing classroom. The comparative study showed that the writing scores and writing product from the framework had an advantage in the development of ESL writing skills.

In assessing the effect of DA accompanied on writing in Iran a few researchers such as Ghahremani and Azarizad (2013), Hashemnezhad and Fatollahzadeh (2015) and Alemi (2015) have conducted studies on the effects of dynamic assessment on process writing. Alemi (2015) conducted a study by investigating the Iranian EFL learners' self-assessment and self-rating to their writing ability as well as the effect of DA in their accuracy. She also investigated the interrelationship among the teacher rating, self-assessment, and self-rating in the writing performance. The participants were twenty-two engineering students who took a writing course as part of a general English course. The data were analyzed using descriptive statistics, correlational analyses, and t-test. The results showed that DA successfully helped Iranian EFL learners to find a better awareness of the characteristics of writing an evaluation. Therefore, they became more accurate in measuring their own writing ability. Hashemnezhad and Fatollahzadeh (2015) investigated fifty Iranian students in a quasi-experimental study to found out the immediate and delayed effects of their writing performance. The pretest was conducted by assigning the students to write two topics in both the experimental and control group. In the experimental group, the DA technique was applied, meanwhile, in the control group, the traditional method was administered. The study concluded that DA was an effective teaching tool to enhance the students' writing performance. The result showed that DA did not only prove to have immediate effects, it also had delayed effects.

Based on the previous studies, it is evident that different model of DA has a positive influence on the development of writing skills of L2 learners. But there is little research to investigate the effect of HAD on the writing of EFL students, especially their descriptive writing. The current study investigated the role of HDA in the students' descriptive writing skill development in Iranian EFL context to find out if the new model of DA had any effect on them and how they would evaluate the model. In light of the above issues, this study sought to address the following research question:

$>$ Is using HDA significantly more effective than non-HDA in improving Iranian EFL learners' descriptive writing?

D Does using HAD have any significant effect on the subskills of descriptive writing (format and content, organization and coherence, and sentence construction and vocabulary) in Iranian EFL learners?

$>$ How do EFL evaluate the proposed HDA model as a means of assessing their writing?

\section{Method}

\subsection{Participant}

The participant in this study were 40 Iranian EFL learners who just enrolled in intermediate English writing 
course at the Omid language institute, Shahrekord branch. All the learners were female and the age of them ranged from 19 to 25. Moreover, they were selected through the Oxford Placement Test (OPT), which was developed by Allen (2004). Also, they were randomly assigned into two groups: 20 learners in the experimental group, and 20 others in the control group. The learners have been studied EFL for several years and they were able to write paragraphs. They attended the class providing practice in writing skills.

\subsection{Instrument}

In this study, three instruments were used for data collection: Oxford Placement Test (OPT, 2004), two descriptive timed-essays, and the HDA questionnaire. The first instrument applied in this research was the OPT to ascertain the proficiency level of participants. The OPT comprises 200 items, containing grammar as well as listening, vocabulary and reading skills. Allen (2004), the composer of the test, declares that the OPT is sufficient of being employed with any number of students of English to guarantee effective, reliable and precise grading and placing of students into classes at all levels from elementary to advanced. According to Allen, the OPT is capable of being utilized with any number of students of English to ensure efficient, reliable and accurate grading and placing of students into classes at all levels from elementary to advanced levels.

Descriptive essays were administered to both control and experimental groups as the pretest and posttest. Two topics, not requiring any special knowledge, were given to the participants. For the pretest, the participants were asked to write a 60-minute descriptive essay on the topic: "Describe a country you would like to visit when you grow up". And for the posttest, they were asked to write on the topic: "Describe the most embarrassing moment of your own life". The number of words in each essay was about 350-400 words. Cares were taken to make the titles of the essays as similar as possible in terms of the complexity of language, readability, and frequency of words. In order to assess the quality of the writing performance of the participants in the pretest and posttest, an analytic scoring rubric developed by Hyland (2003) were used. Meanwhile, the interrater reliability indices for the pretest and posttest essays were found to be .96 and .97 respectively.

A self-made questionnaire on HDA was used to collect the data regarding how they would evaluate the model for descriptive writing. Having obtained a good command of the concept of HDA, the concepts were changed into items/statements. In all, 42 items were extracted each tapping one aspect or major issue in HDA. The list was then shown to an expert, a Ph.D. candidate in TEFL, who reviewed the whole list and made some comments on the items. The questionnaire was then revised based on the comments made. Accordingly, the number of items was reduced and some items were totally discarded or replaced by new items. Then, the same expert rechecked the revised questionnaire. Besides, the questionnaire was sent to the second expert for its validity. At this stage, some minor revisions were made in the questionnaire. The final version of the questionnaire was set based on a 5-point Likert scale, ranging from 1 (Strongly disagree) to 5 (Strongly agree), producing a score between 1 and 5 for each item (Yamini \& Rahimi, 2007). Moreover, having undertaken the test of reliability, several items were eliminated from the questionnaire. Hence, the number of items in the final version was 18 . To check the reliability of the questionnaire, it was piloted on 30 EFL learners to check the suitability of the questionnaire for the main study. The Cronbach's alpha obtained for the questionnaire was .88 , which was relatively acceptable.

\subsection{Data collection and analysis procedures}

The data were collected in several steps. First, OPT (2004) was administered to a sample of around 45 EFL learners to select a homogeneous sample. The researchers selected 40 of the learners who gained the score for the intermediate level. They all enrolled in an intermediate English course in the spring semester of 2018. The 20 of the participants who attended the even day were considered as a control group and those 20 participants with the same condition who attended the odd days, were considered as an experimental group. Second, the teachers trained the participants in both experimental and control groups, before administering the pretest. The same content was chosen to be thought by the teacher for the two groups, and the teacher used the same materials for 
Roohani, A., \& Shafiee Rad, H.

teaching in both groups.

As earlier discussed, pre- and posttests were used in order to answer the research question regarding the impact of the HDA on the improvement of 40 EFL learners' descriptive writing in Iran. The pre- and posttests included two main components: (1) a non-dynamic essay test component given to the 40 participants in the control and experimental group, and (2) a dynamic component in the form of mediation session between the mediator and the participants in the experimental group. The participants in the experimental group were informed about the mistakes in the pretest and received remedy on the weak points. The mediator provided the learners in the experimental group with correction, explanation, hinting, questions, non-verbal cues, and translation. The experimental group received the HDA instruction for four weeks, in addition to pre and posttest. During the treatment, they had to write a descriptive essay every night and send it to the mediator in an email in order to improve their writing. The mediator had to read the participants' email one by one and explained to them the areas of difficulty and mistakes made by each of the participants. During the instruction, the teacher (mediator) observed the participants and helped them correct their mistakes by hinting, and asking the question. After the instruction, all the participants in both the experimental and control group were asked to write a timed-essay descriptive essay (Describe a country you would like to visit when you grow up) .

The participants in the control group were assessed just in the traditional method, and they were asked every session to write an essay. Traditional assessment scales were limited in dependence on motor responsiveness and thus were of limited or no application to patients receiving paralytics or those requiring very high doses of anxiolytics. They did not receive mediation or dynamic assessment. In the four weeks of treatment for the experimental group, the learners in the control group had to write a descriptive essay every week and the teacher scores them and reports the results. As the teacher of control group asserted learners were not much interested in writing class as they are in other skills.

After the four weeks, the posttest was administered by inviting them to write another descriptive timed-essay (Describe the most embarrassing moment of your own life) both for the experimental and control group. Like the pretest, the posttest was also administered through dynamic and non-dynamic assessment. The control group had just received the non-dynamic assessment. But the experimental group received a non-dynamic and dynamic assessment. That is, they received feedback and mediation through the pre- and post-test and also four weeks of negotiation with a mediator between them. The mediator had observed the testing sheet in the posttest, too, and gave them help in their errors in the experimental group.

To increase the dependability of the data, both pretest and posttest timed-essays were graded by two raters and interrater reliability was computed. The interrater reliability indices for the pretest and posttest were found to be .96 and .97 respectively. Finally, the pretest-posttest scores were compared to address the first two research questions for the study. Given pretest and posttest design of the study, analysis of covariance (ANCOVA) was used as a statistical tool for data analysis (to answering the first question of the study). To discover the effect of HDA on the subskills of descriptive writing i.e., the focus of the second question of this research, the paired sample $t$-tests were used. The descriptive statistics were used to answer the third research question regarding the evaluation of the proposed HDA model as a means of assessing the participants' writing in the experimental group.

\section{Results}

To compare the performance of HDA (experimental) and non-HDA (control) groups, the descriptive writing scores in both groups were obtained. Table 1 shows the descriptive statistics of writing scores in both groups. According to Table 1, the pretest means scores in the non-HDA and HDA groups were 56.55 and 56.40; that is, the mean score in the non-HDA was a little greater than the HDA group. However, the difference was not great. According to Table 1, the difference in the posttest means scores of the HDA group (88) was more than non-HDA (57.25) group, with the HDA group receiving higher descriptive writing gains. Also, the data in Table 2 shows that 
Effectiveness of Hybrid Dynamic Assessment in L2 learners' descriptive writing development

the mean scores increased from the pretest to the posttest in both groups, indicating the better performance of the two groups after the pretest.

\section{Table 1}

Descriptive statistics of writing scores in both groups

\begin{tabular}{llccccccc}
\hline \multicolumn{1}{c}{ Variable } & \multicolumn{1}{c}{ Groups } & $n$ & Min & Max & Mean & SD & Skewness & Kurtosis \\
\hline \multirow{2}{*}{ Pretest } & Control & 20 & 32 & 81 & 56.55 & 12.81 & -.035 & .421 \\
& Experimental & 20 & 31 & 80 & 56.40 & 14.68 & -.261 & -1.079 \\
\multirow{3}{*}{ Posttest } & Control & 20 & 32 & 81 & 57.25 & 12.59 & .070 & .79 \\
& Experimental & 20 & 75 & 100 & 88.00 & 8.18 & .031 & -1.332 \\
\hline
\end{tabular}

To find out the answer to the first research question of study, concerning the comparative effects of the HDA and non-HDA instructions on the participants' descriptive writing performance, Analysis of Covariance (ANCOVA) was conducted after checking the homogeneity of the groups in terms of writing scores in both groups, equality of the variance across both groups, the reliability of the covariance i.e., the pretest writing scores, and non-significant interaction effect between the covariance and the treatment. The results of the ANCOVA was summarized in Table 2.

Table 2

Analysis of covariance for the treatment effects on posttest score

\begin{tabular}{|c|c|c|c|c|c|c|c|}
\hline \multirow{2}{*}{\multicolumn{2}{|c|}{ Type of Instruction }} & \multicolumn{6}{|c|}{ Achievement } \\
\hline & & \multicolumn{2}{|c|}{ Observed Mean } & \multicolumn{2}{|c|}{ Adjusted Mean } & $S D$ & \multirow{2}{*}{$\frac{n}{20}$} \\
\hline Control Group & & & & & & 12.73 & \\
\hline HDA group & & & & & & 11.43 & 20 \\
\hline Source & SS & $d f$ & $\mathrm{M}$ & & $F$ & & \\
\hline Corrected Model & 126.68 & 2 & & .32 & 205.11 & & \\
\hline Intercept & 258.80 & 1 & & 3.80 & 84.10 & & \\
\hline Pretest. & 314.05 & 1 & & 7.05 & 102.43 & & \\
\hline Group & 912.39 & 1 & & .39 & $297.03 *$ & & \\
\hline Error & 113.69 & 37 & & & & & \\
\hline
\end{tabular}

As Table 2 revealed, the model was significant and the HDA group performed better than the traditional group in the posttest, so the HDA group significantly performed better than the other group. The above statistics point to the conclusion that the HDA group significantly performed better than the non-HDA group on the descriptive writing after the treatment. In other words, the HDA instruction had a more significant impact on the descriptive writing of Iranian EFL students.

To answer the second question of this study, which concerned whether using HAD had any significant effect on the subskills of descriptive writing (format and content, organization and coherence, and sentence construction and vocabulary) in Iranian EFL learners' the paired sample $t$-tests were conducted between the pretest and posttest scores on the subskills of writing in the experimental group. The results are summarized in Table 3.

As Table 3 revealed, the model was significant, that is, by using HDA in the experimental group all the subcomponents of descriptive writing improved. There were statistically significant differences in the areas of format and content, organization and coherence, sentence construction and vocabulary. Therefore, using HDA in teaching descriptive writing to the Iranian EFL students improved all the areas of writing. 
Roohani, A., \& Shafiee Rad, H.

\section{Table 3}

Paired samples t-tests comparing pretest and posttest scores on the subskills of writing in an experimental group

\begin{tabular}{lcccc}
\hline \multicolumn{1}{c}{ Variables } & $\begin{array}{c}\text { Pretest } \\
\text { Mean }(S D)\end{array}$ & $\begin{array}{c}\text { Posttest } \\
\text { Mean }(S D)\end{array}$ & $t$ value & $p$ value \\
\hline Format and Content & $22.40(7.32)$ & $27.15(7.55)$ & -7.380 & .000 \\
Organization and Coherence & $13.28(4.01)$ & $15.28(3.44)$ & -4.322 & .000 \\
Sentence Construction and Vocabulary & $21.18(5.76)$ & $30.18(9.60)$ & -14.575 & .000 \\
\hline
\end{tabular}

To find out the answer to the third research question of the study, which was intended to see how the students in the experimental group would evaluate the HDA model, descriptive statistics of the items in the HAD questionnaire were obtained. Table 4 reports the mean scores and standard deviations for each item and the overall items in the questionnaire.

\section{Table 4}

Descriptive statistics for the items in the HDA questionnaire

\begin{tabular}{|c|c|c|c|}
\hline & Items & Mean & SD \\
\hline 1 & I found the instruction in the writing course very effective. & 4.06 & .674 \\
\hline 2 & The instruction in the writing course helped me remove errors and learn better. & 4.26 & .661 \\
\hline 3 & The support of the instructor on my writing helped me be more relaxed. & 3.66 & .645 \\
\hline 4 & Interaction with the instructor through email improved my writing. & 3.66 & .625 \\
\hline 5 & I could concentrate more when the instructor checked my paper after finishing the essay tests. & 3.66 & .601 \\
\hline 6 & The interaction between the instructor and I increased my self-confidence in writing. & 3.93 & .572 \\
\hline 7 & $\begin{array}{l}\text { The instructor's hints throughout the course made me more aware of my weak points in } \\
\text { writing. }\end{array}$ & 4.20 & .617 \\
\hline 8 & The instructor's comments on my writing were effective in gaining a high score in writing. & 4.13 & .656 \\
\hline 9 & $\begin{array}{l}\text { The instructor's comments on my writing in the writing course helped me increase my speed in } \\
\text { writing. }\end{array}$ & 4.66 & .690 \\
\hline 10 & I actually enjoyed the instruction in the writing course. & 3.73 & .719 \\
\hline 11 & The writing was more fun with the instructor's approach in the writing course. & 3.73 & .654 \\
\hline 12 & I became interested in writing when the instructor helped me through email and negotiation. & 4.13 & .678 \\
\hline 13 & $\begin{array}{l}\text { Through the instructor's observation and monitoring in the course, I became more aware of } \\
\text { format and organization in my descriptive writing. }\end{array}$ & 3.60 & .654 \\
\hline 14 & $\begin{array}{l}\text { Through the instructor's observation and monitoring in the course, I became more aware of } \\
\text { coherence in my writing. }\end{array}$ & 4.13 & .765 \\
\hline 15 & $\begin{array}{l}\text { Through the instructor's observation and monitoring in the course, I became more aware of } \\
\text { sentence construction in descriptive writing. }\end{array}$ & 3.20 & .543 \\
\hline 16 & The interactive nature of the instructor's approach in the writing course was really helpful. & 4.34 & .623 \\
\hline 17 & The hints during the essays helped me activate my knowledge. & 4.60 & .624 \\
\hline 18 & Overall, I am satisfied with the experience through this writing course. & 4.62 & .654 \\
\hline Overall & & 4.01 & .647 \\
\hline
\end{tabular}

According to Table 4, all the mean scores of the items were above 3.00, that is to say, above the median (2.5). This means that the participants in the experimental group after the HDA treatment expressed their agreement with most of the statement in the HDA questionnaire. The highest mean score belonged to items $9(M=4.66, S D$ $=.690), 18(M=4.62, S D=.654)$, and $17(M=4.60, S D=.624)$. The participants in the experimental group 
expressed their agreement with the proposition stating that the instructor's comments, guidance, observation throughout the course increased their writing speed and activated the participants' passive knowledge. In general, the participants evaluated the HDA model of dynamic assessment positively. According to the data, the participants in the experimental group thought that the HDA model of assessment improved their writing skills in the class. The lowest mean score belonged to items $15(M=3.20, S D=.543), 13(M=3.60, S D=.654)$, and 11 $(M=3.73, S D=.654)$ together with $10(M=3.73, S D=.719)$, indicating that they were less aware of format and organization, sentence construction. Also, the data showed that descriptive writing was somehow hard for them, but the HAD method helped them a lot to solve their problems.

\section{Discussion}

Human beings are open rather than closed systems, meaning that cognitive abilities can be developed in a variety of ways, depending on the presence and the quality of appropriate forms of interaction and instruction. HDA may provide a new form of instruction for assessing language skills including writing. In fact, the foundation of HDA is driven by the needs for an alternative assessment method to the widely used standardized testing which has been criticized for being inadequate for writing assessment (Sadek, 2011). The present study proposed an alternative assessment method for descriptive writing and explored the HDA method in comparison to non-HDA method in improving Iranian EFL learners' descriptive writing. The results of the statistical analysis indicated that the writing means scores improved from the pretest to the posttest in both HDA and non-HDA groups of the study. However, the EFL learners in the HDA group, as compared with the learners in the non-HDA group (the traditional way), had greater performance in descriptive writing test tasks. It can be argued that a method of assessment which consists of the interventionist and interactionist model of DA can improve Iranian EFL learners' skill in descriptive writing. In fact, pre- and posttest from the interventionist model of DA together with the mediator's comments in the HAD through correction, explanation, elicitation, hinting, questions, non-verbal cues, negotiation with the participants, and interaction through emails improved the EFL learners' descriptive writing skill. Thus, the combination of the features from interventionist and interactionist models made it a powerful way of assessing the EFL participants' writing skill.

The finding of the current research has supported the finding of Sadek (2011) research on the HDA model of assessing. Sadek's study showed that the HDA model of assessing had a positive effect on English language learners. The current study also showed that using this method in teaching descriptive writing to EFL learners in Iran would lead to positive results. Also, the above findings support the results reported by several studies conducted on the use of different DA models in L2 (e.g., Aljaafreh \& Lantolf, 1994; Anton, 2009; Ableeva, 2008; Kozulin \& Garb, 2001; Poehner, 2005). For example, Aljaafreh and Lantolf (1994) reported the effectiveness of DA on Chinese students' L2 grammar in writing in Canada. Whereas Aljaafreh and Lantolf focused on one aspect of writing, which was grammar, the present study showed the effectiveness of the HDA in improving three areas of writing aspects. The results of $t$-tests results showed that the areas of format and content, organization and coherence, sentence construction and vocabulary improved significantly after using the HAD method and there were significant differences between the control group and the experimental one in these areas of writing.

As to the third research question, the results of the present study revealed that the EFL learners in the HDA group agreed with the use of the HDA method regarding a writing class. They reported that the aforementioned method of assessment made them more reflective. It seems that participants of the present study were in favor of the HDA model very much for the same reasons which actually would distinguish HDA methods from non-HDA methods. They indicated that it was effective because of the help they received from the mediator and problem-solving strategies implemented in their class.

The results indicated that the process of writing integrated with HDA could improve the EFL learners' skill in writing description and build up their writing confidence. The teacher's mediation stimulated the learners' responsiveness through which their enthusiasm for engagement in the writing process could rise. The mediator 
Roohani, A., \& Shafiee Rad, H.

tried to act in the ZPD and helped them move from their present cognitive ability level to the future level. Face to face interaction with the mediator showed the possibility of transferring what they learned in their writing tasks to future situations. This way their confidence in writing improved and their attitudes towards descriptive writing turned out to be significantly positive.

\section{Conclusion and implication}

In the present study, a HDA assessment has been introduced to assess EFL learners' learning in an interactive manner in the area of writing. In fact, the present study examined the effect of HAD, which is the integration of the aspects from both interactionist and interventionist DA models, on some Iranian EFL learners' descriptive writing skill. The results of the present study showed that the use of the HDA method of assessment played an important role in improving EFL descriptive writing performance. In fact, the HDA helped the EFL learners recognize the purpose of their writing and improved the quality of their writing performance. Based on the results of the current study, HDA can lead to the improvement of L2 writing skill and make L2 learners focus on their individual weaknesses in writing. Also, the findings of the current study tend to direct the attention of L2 teachers in writing courses toward the importance of utilizing HDA as a possible way to move away from the traditional way of assessment so as facilitate L2 writing development.

Furthermore, the results of the current study revealed that the function and content, organization coherence, and sentence construction and vocabulary subcomponents of descriptive writing improved more in the HDA group than control one. By implications, teachers should be given more authority to implement HDA in the classroom to see how this alternative method can improve the subskills of writing in their L2 classes. Also, L2 materials developers should also pay attention to the contribution of HAD when developing instructional materials for L2 learners.

In addition, the findings indicated that the EFL learners in the HAD had a positive attitude toward using HDA in the class. The data showed that through the comments they received from the instructor i.e. mediator, their attitude towards writing skill changed. They believed that the introduction of the HDA method in the writing classroom helped them overcome many of the problems associated with the use of traditional testing and assisted them to better evaluate their own descriptive writing skill in the process of L2 development. Thus, the results suggest that the gap between assessment and instruction in L2 writing can be bridged more through HDA.

\section{References}

Ableeva, R. (2009). Dynamic assessment of listening comprehension in second language learning (Unpublished doctoral dissertation). The Pennsylvania State University, University Park, PA.

Alemi, M. (2015). The impact of dynamic assessment on Iranian EFL students' writing self-assessment. TELL, 9(1), 145-169.

Aljaafreh, A., \& Lantolf, J. P. (1994). Negative feedback as regulation and second language learning in the zone of proximal development. The Modern Language Journal, 78, 465-483.

https://doi.org/10.1111/j.1540-4781.1994.tb02064.x

Allen, L. (2004). The Oxford placement test. Oxford University Press.

Anton, M. (2009). Dynamic assessment of advanced language learners. Foreign Language Annals, 42(3), 576-598. https://doi.org/10.1111/j.1944-9720.2009.01030.x

Birjandi, P., \& Ebadi, S. (2012). Microgenesis in dynamic assessment of L2 learners' socio-cognitive development via web 2.0, [Electronic version]. Procedia-Social and Behavioral Sciences, 32, 34-39. https://doi.org/10.1016/j.sbspro.2012.01.006

Brown, H. D. (2003). Language assessment: Principles and classroom practices. New York: Pearson Longman.

Budoff, M., \& Corman, L. (1976). Effectiveness of a learning potential procedure in improving problem-solving skills of retarded and non-retarded children. American Journal of Mental Deficiency, 81, 260-264.

Campione, J. C., \& Brown, A. L. (1987). Linking dynamic assessment with school achievement. In C. S. Lidz 
Effectiveness of Hybrid Dynamic Assessment in L2 learners' descriptive writing development

(Ed.), Dynamic assessment: An interactional approach to evaluating learning potential (pp. 82-115). New York: Guilford.

CarlHaywood, H. (2012). Dynamic assessment: A history of fundamental ideas. Journal of Cognitive Education and Psychology, 11, 232-253. https://doi.org/10.1891/1945-8959.11.3.217

Chaiklin, S. (2003). The zone of proximal development in Vygotsky's analysis of learning and instruction. In A. Kozulin, B. Gindis, V. Ageyev, \& S. Miller (Eds.), Vygotsky's educational theory in cultural context (pp. 39-64). Cambridge University Press. https://doi.org/10.1017/CBO9780511840975.004

Charney, D. (1984). The validity of using holistic scoring to evaluate writing: A critical overview. Research in the Teaching of English, 18, 65-81.

Chomsky, N. (1986). Knowledge of language. New York: Praeger.

Corman, L., \& Budoff, M. (1973). A comparison of group and individual training procedures on the Raven Learning Potential Measure. Cambridge: Research Institute for Educational Problems.

Deshler, D., Palincsar, A. S., Biancarosa, G., \& Nair, M. (2007). Informed choices for struggling adolescent readers: A research-based guide to instructional programs and practices. Newark, DE: International Reading Association.

Dunn, K. E., \& Mulvenon, S. W. (2009). A critical review of research on formative assessments: The limited scientific evidence of the impact of formative assessments in education. Practical Assessment Research \& Evaluation, 14(7), 1-11.

Elbow, P., \& Belanoff, P. (1986). Portfolios as a substitute for proficiency examinations. College Composition and Communication, 37(3), 336-339. https://doi.org/10.2307/358050

Feuerstein, R., Rand, Y., \& Hoffman, M. (1979). The dynamic assessment of retarded performers: The learning potential assessment device (LPAD). Baltimore: University Park Press.

Ghahramani, D., \& Azarizad, R. (2013). The effect of dynamic assessment on EFL process writing: Content and organization. International Research Journal of Applied and Basic Sciences, 4(4), 874-878.

Guthke, J., \& Wingenfeld, S. (1992). The learning test concept: origins, states of the art, and trends. In H. C. Heywood \& D. Tzuriel (Eds.), An interactive assessment (pp. 64-93). New York: Springer-Verlag.

Hamp-Lyons, L. (1990b). Second language writing: Assessment issues. In B. Kroll (Ed.), Second language writing: Research insights for the classroom (pp. 69-87). New York: Cambridge University Press.

Hamp-Lyons, L. (Ed.). (1990a). Assessing second language writing in academic contexts. Norwood, NJ: Ablex.

Hashemnezhad, H., \& Fatollahzadeh, F. (2015). The immediate and delayed effect of dynamic assessment on the improvement of Iranian EFL learners' writing performance. International Journal of Language Learning and Applied Linguistics World, 8(2), 193-209.

Haywood, H. C., \& Lidz, C. S. (2007). Dynamic assessment in practice: Clinical and educational applications. New York: Cambridge University Press.

Haywood, H. C., Brown, A. L., \& Wingenfeld, S. (1990). Dynamic approaches to psychoeducational assessment. School Psychology Review, 19(4), 411-422.

Huot, B. (1990). The literature of direct writing assessment: major concerns and prevailing trends. Review of Educational Research, 60(2), 237-263. https://doi.org/10.3102/00346543060002237

Hyland, K. (2003). Second language writing. London: Cambridge University Press. https://doi.org/10.1017/CBO9780511667251

Joseph C., Campione, M., \& Brown, L. A. (1987). Dynamic assessment: One approach and some initial data. Cambridge, Massachusetts.

Kachru, B. B. (1992). The other tongue: English across cultures (2nd ed.). Urbana: University of Illinois Press. Kizlik, B. (2009). Measurement, assessment, and evaluation in education. Boca Raton, FL: ADPRIMA.

Kozulin, A., \& Garb, E. (2002). Dynamic assessment of EFL text comprehension. School Psychology International, 23(1), 112-127. https://doi.org/10.1177/0143034302023001733

Lantolf, J. P., \& Poehner, M. E. (2004). Dynamic assessment of L2 development: Bringing the past into the future. Journal of Applied Linguistics, 1(2), 49-72. https://doi.org/10.1558/japl.v1i1.49

Lantolf, J. P., \& Poehner, M. E. (2006). Sociocultural theory and the teaching of second languages. London, UK: Equinox. 
Roohani, A., \& Shafiee Rad, H.

Lantolf, J. P., \& Poehner, M. E. (2007). Dynamic assessment in the foreign language classroom. A teacher's guide. University Park, PA: CALPER Publications.

Lantolf, J. P., \& Thorne. S. L. (2004). The sociogenesis of second language development. Oxford University Press.

Lantolf, J. P., Poehner, M. E. (2011). Dynamic assessment in the classroom: Vygotskian praxis for second language development. Language Teaching Research, 15, 11-33. https://doi.org/10.1177/1362168810383328

Larsen-Hall, J. (2010). A guide to doing statistics in second language research using SPSS. New York: Routledge.

Lidz, C. S. (Ed.). (1987). Dynamic assessment: An interactional approach to evaluating learning potential. New York: Guilford.

Mason, L. H., Benedek-Wood, E., \& Valasa, L. (2009). Teaching low-achieving students to self-regulate persuasive quick write responses. Journal of Adolescent \& Adult Literacy, 53(4), 302-312. https://doi.org/10.1598/JAAL.53.4.4

McNamara, T., \& Roever, C. (2006). Language testing: The social dimension. Oxford: Blackwell.

Messick, S. (1989). Test validity and the ethics of assessment. American Psychologist 35(11), 1012-1027. https://doi.org/10.1037/0003-066X.35.11.1012

Meyers, A. (2009). Writing with confidence (9th ed.). New Jersey: Pearson Education Inc.

Miao, T., \& Lv, M. (2013). Dynamic assessment in ESL writing classroom. Paper presented at the International Conference on Education Technology and Management Science (ICETMS), Nanjing, Jiangsu, China. https://doi.org/10.2991/icetms.2013.1

Nassaji, H., \& Tian, J. (2010). Collaborative and individual output tasks and their effects on learning English phrasal verbs. Language Teaching Research, 14, 397-419. https://doi.org/10.1177/1362168810375364

Perakyla, A. (2008). Analyzing talk and text. In N. K., Denzin, \& Y. S., Lincoln (Eds.), Collecting and interpreting qualitative materials (3rd ed., pp. 869-886). Thousand Oaks, CA: Sage.

Pilipović, T. (2017). The effect of testing on teaching. New York: Sage Publications.

Poehner, M. E. (2005). Dynamic assessment of oral proficiency among advanced L2 learners of French (Unpublished doctoral dissertation). The Pennsylvania State University, University Park.

Poehner, M. E., \& Lantolf, J. P. (2005). Dynamic assessment in the language classroom. Language Teaching Research, 9, 233-265. https://doi.org/10.1191/13621688051r166oa

Poehner, M. E. (2008). Dynamic Assessment: A Vygotskian Approach to Understanding and Promoting Second Language Development. Berlin: Springer Publishing. https://doi.org/10.1007/978-0-387-75775-9

Rubin, H. J., \& Rubin, I. S. (2005). Qualitative interviewing: The art of hearing data (2nd ed.). New York: Sage Publications.

Sadeghi, K., \& Khanahmadi, F. (2011). Dynamic assessment of L2 grammar of Iranian EFL learners: The role of the mediated learning experience. International Journal of Academic Research, 3(2), 931-936.

Sadek, N. (2011). Dynamic assessment and second language writing: toward a hybrid dynamic assessment model in assessing English Language Learners (ELL). Berlin: Lambert Academic Publishing.

Sadek, N. (2015). Dynamic Assessment (DA): Promoting writing proficiency through assessment. International Journal of Bilingual \& Multilingual Teachers of English, 2(2), 113-123. https://doi.org/10.12785/ijbmte/030201

Sadek, N. S. (2011). A hybrid dynamic assessment (HDA) model of essay writing by English language learners (ELL): An exploratory qualitative study (Unpublished doctoral dissertation). Indiana University of Pennsylvania.

Shabani, K. (2012). Dynamic assessment of L2 learners' reading comprehension processes: A Vygotskian perspective. Procedia-Social and Behavioral Sciences, 32, 321-328. https://doi.org/10.1016/j.sbspro.2012.01.047

Shrestha, P., \& Coffin, C. (2012). Dynamic assessment, tutor mediation, and academic writing development, [Electronic version]. Assessing Writing, 17, 55-70. https://doi.org/10.1016/j.asw.2011.11.003

Silva, T. (1993). Toward an understanding of the distinct nature of L2 writing: The ESL research and its 
implications. TESOL Quarterly, 27(4), 657-677. https://doi.org/10.2307/3587400

Sternberg, R. J., \& Grigore nko, E. L. (2002). Dynamic testing: The nature and measurement of learning potential. Cambridge: University of Cambridge.

Suleiman, M., F. (2000). The process and product of writing: Implications for elementary school teachers. Paper presented at the California Association for Bilingual Education Conference, San Francisco, CA.

Summers, R. (2008). Dynamic assessment: Towards a model of dialogic engagement. Retrieved from http://scholarcommons.usf.edu/etd/521

Tzuriel, D. (2000a). The seria-think instrument: A novel measure for assessment and intervention in a seriational-computational domain. School Psychology International, 21(2), 173-190. https://doi.org/10.1177/0143034300212005

Tzuriel, D. (2001). Dynamic assessment of young children. New York: Kluwer Academic/Plenum Press. https://doi.org/10.1007/978-1-4615-1255-4

Tzuriel, D., \& Klein, P. (1987). Assessing the young child: Children's' analogical thinking modifiability. In C.S. Lidz (Ed.), Dynamic assessment: An interactional approach to evaluating learning potential (pp. 268-287). New York: Guilford Press.

Vygotsky, L. S. (1978). Mind in society: The development of higher psychological processes. Cambridge: Harvard University Press.

Vygotsky, L.S. (1998). The problem of age. In R. W. Rieber (Ed.), The collected works of L. S. Vygotsky (pp. 187-206). New York: Plenum.

Xiaoxiao, L., \& Yan, L. (2010). A case study of dynamic assessment in EFL process writing. Chinese Journal of Applied Linguistics, 33(1), 24-40. Retrieved from http://www.celea.org.cn/teic/89/10042202.pdf

Yamini, M., \& Rahimi, M. (2007). A guide to statistics and SPSS for research in TEFL, linguistics and related disciplines. Shiraz: Koushamher.

Yancey, K. B. (1999). Looking back as we look forward: Historicizing writing assessment. College Composition and Communication, 50(3), 483-503. https://doi.org/10.2307/358862

Yin, R. (1994). Case study research: Design and methods (2nd Ed.). Beverly Hills, CA: Sage publications. 
Roohani, A., \& Shafiee Rad, H. 